\title{
O poder e a biopolítica: as fronteiras que separam a vida digna da vida indigna de ser vivida
}

\author{
Power and biopolitics: the boundaries of life worthy of life and the unworthy of being lived
}

\section{Gabriel Silva Rezende}

Como citar esse artigo. Rezende, GS. O poder e a biopolítica: as fronteiras que separam a vida digna da vida indigna de ser vivida Revista Mosaico. 2018 Jan./Jun.; 09 (1): 44-49.

\begin{abstract}
Resumo
O presente trabalho tem como objetivo analisar quanto à localização do espaço da biopolítica nos contornos da noção do poder soberano e a vida nua, principalmente, nas formas de pensar sobre as práticas políticas que não se enquadram facilmente em categorias tradicionais, como a noção de biopoder. Abordaremos sob o esquema teórico de Agamben e Foucault, ressaltando a característica na qual o poder soberano não mais repousa sob a direção de apenas um sujeito dotado de características excepcionais. No intuito de desvelar, sob a ótica dos autores, como o desenvolvimento das intervenções biopolíticas ocorre, cada vez mais, de maneira velada, amparadas por um saber-poder que as legitima, e emanadas de centros de poder cada vez mais descentralizados. Caracterizando um binômio: a vida qualificada (bios), a vida que merece ser vivida em plenitude e protegida por ser incluída numa comunidade política (como na pólis) e instituída de direitos; e a mera vida (zoé), a vida nua não qualificada, desprovida de garantias e exposta à morte.

Palavras-Chave: Biopoder; Poder Soberano; Vida Nua.
\end{abstract}

\begin{abstract}
The present work aims to analyze the location of the space of biopolitics in the contours of the notion of sovereign power and bare life, especially, in ways of thinking about political practices that do not easily fall into traditional categories, such as the notion of biopower. We will approach under the theoretical scheme of Agamben and Foucault, emphasizing the characteristic in which the sovereign power no longer rests under the direction of only a subject endowed with exceptional characteristics. In order to reveal, from the point of view of the authors, how the development of biopolitical interventions occurs, increasingly, in a veiled way, supported by a knowledge-power that legitimates them, and emanating from increasingly decentralized centers of power. Characterizing a binomial: qualified life (bios), life that deserves to be lived to the fullest and protected by being included in a political community (as in the polis) and instituted of rights; and mere life (zoé), naked life unqualified, devoid of guarantees and exposed to death.

Keywords: Biopower; Sovereign Power; Bare Life.
\end{abstract}

\section{Introdução}

O presente trabalho buscará elucidar as análises de dois dos grandes filósofos pós-modernos, Michel Foucault e Giogio Agamben, que marcaram de forma profunda não somente a área das Ciências Sociais, mas das Ciências Humanas como um todo. Portanto, o objetivo deste artigo concentrar-se-á em descrever as questões nevrálgicas de cada um, bem como a complementariedade e os graus de divergência desses dois autores, quanto aos seus "fios condutores" teóricos como as metodologias empregadas. Contemporâneos entre si, ambos foram sorvidos pelos diferentes processos significativos da pós-modernidade ou modernidade tardia que não somente modificaram as relações de acumulação de capital, mas também os relacionamentos da vida social que foram acrescidos ou reformulados de novos significados. Os conceitos centrais destes autores, entrelaçam-se sobre: disciplina, noções de poder, soberania, estrutura e história. E, principalmente, nas formas de pensar sobre as práticas políticas que não se enquadram facilmente em categorias tradicionais, como a noção de biopoder. Dessa forma, o sujeito tem sua vida auferida de diversas maneiras pelo capitalismo, não somente na esfera social, em que o sistema imperativo se torna também um meio difusor e característico dos processos econômicos. Por conseguinte, esses intelectuais buscaram analisar e discutir as imbricações entre o fazer político e o social da contemporaneidade.

Nessa perspectiva, biopolítica pode ser entendida enquanto tecnologia de governo através da qual os mecanismos biológicos dos indivíduos passam a

Afiliação dos autores: † Bacharel em Relações Internacionais (UCAM), Mestrando em Sociologia Política pelo Instituto Universitário de Pesquisas do Rio de Janeiro (IUPERJ) e pesquisador do Laboratório de Estudos da Cidade e da Cultura da Universidade Candido Mendes, Rio de Janeiro, Brasil. 
integrar o cálculo da gestão do poder. Ou seja, a relação dos sujeitos com o poder foi reajustada numa forma de acomodação biológica promovida pelo Estado, nutrindo um aspecto de "adestramento dos corpos" e sua capacidade de torna-los "dóceis" (disciplinados/ moldados pelo Estado). Sendo que esses "novos" mecanismos biopolíticos revelaram-se indispensáveis para o desenvolvimento do modo de produção capitalista na medida em que os fenômenos populacionais eram equacionados aos processos de acumulação do capital, visto as grandes ações sanitaristas em todo mundo, como um exemplo. Bem como a noção genealógica, no sentido de que o sujeito é gerado/construído por meio de práticas políticas inerentes a lógica de produção saber poder, e sua perpetuação de poder ao longo da história deriva-se da permanência da técnica, principalmente do controle e disciplina. Agamben segue a mesma noção foucultiana realçada acima, ao propor o conceito de homo sacer, poder soberano e o estado de exceção, uma vez que o autor expõe o poder e sua continuidade/ permanência como instância capaz de determinar e traçar o tênue limite entre a vida protegida e vida exposta à morte, politizando o fenômeno da vida.

\section{As capilaridades do poder foucaultiano}

Foucault foi um dos intelectuais pioneiros a romper com a teoria política clássica (mainstream) sobre as relações de poder que permeia toda vastidão da teia social. Ao contrário da noção cristalizada de poder pautada na soberania e em sua governabilidade, como uma unidade monolítica ${ }^{1}$, o filósofo francês propõe uma política de multiplicidade diante da noção de poder. Ao contrastar as multiplicidades das artes de governar à unidade política da soberania.

Desta maneira, Foucault não adota uma noção substancialista de poder, uma vez que poder, na sua compreensão, é um jogo de forças constantemente alterado e passível de mutação pelas relações entre os sujeitos, seus grupos e instituições. O poder, portanto, é "uma multiplicidade de correlações de forças imanentes ao domínio onde se exercem e constitutivas de sua organização". (FOUCAULT, 1977, p. 88) Isto é, o autor entende que as relações de poder consistem num campo de múltiplas possibilidades de ação. Agir sobre a população, sobre as ações dos outros e agir sobre a própria conduta (governos de si mesmo), nesse sentido a macropolítica torna-se indissociável a micropolítica. Assim, "o poder está em toda parte; não porque englobe tudo, e sim, porque provém de todos os lugares" .(FOUCAULT, 1988, p. 103)

Dessa forma, os micropoderes atuam sobre os corpos dos indivíduos, por meio de um programa minucioso de estratégias de saber-poder, em que o modelo da disciplina se difundiu e expandiu para as instituições sociais (família, escolas, empresas, quartéis etc.), cujo objetivo primordial é extrair dos corpos individuais o máximo da capacidade produtiva, a fim de torna-los dóceis e úteis; num jogo de forças dentro de um processo de submissão e controle dos corpos pelo poder disciplinar, que circunscreve de maneiras distintas, e historicamente, de acordo com os regimes políticos ou instituições, de modo a constituir um modo de impulsão do capitalismo.

Nesse sentido, a relação de poder sofreu adaptações no qual o controle social passa a ser feito através de um regime de ordens impostas dando origem a uma sociedade disciplinar e de controle. Mais do que vigiar, era preciso construir um sistema de poder capaz de moldar o indivíduo, transformando em um indivíduo dócil, útil e disciplinado, como assevera Foucault (1988). A "sociedade de segurança", como ele a denomina, são as sociedades modernas ${ }^{2}$, em que as técnicas biopolíticas estão inseridas nos cálculos do governo. Essa nova forma de organização social marcou uma ruptura no discurso científico com a valorização do saber (indispensável para os regimes políticos) nos campos da medicina e da estatística. É através deles que o biopoder é instrumentalizado, permitindo que o Estado o exerça. Por conseguinte, a ordem jurídica integra-se cada vez mais ao conhecimento médico, promovendo uma intervenção reguladora na vida dos indivíduos. (FOUCAULT, 1988, p. 135) O biopoder nas sociedades, desenvolve-se como um mecanismo continuo de regulação e de correção de comportamentos, deslocando a lei e as instituições jurídicas para uma condição de subserviência a essas práticas, de modo que, as leis vão se integrando, paulatinamente, aos aparelhos cujas funções são, primordialmente, reguladoras.

Assim, a compreensão do sentido do conceito de biopoder, até então trabalhado, nos traz considerações sobre a concepção tradicional (jurídico-política) do poder - em voga - como instância unificada na figura do Estado e do Soberano, ativo apenas no sentido vertical, sendo imposto por meio da repressão e da lei entre o espaço do possível e do permitido. Para Foucault, o poder não é concebido nem como violência legalizada nem como a violência que escapa à lei, pois, as relações de poder não se constituem na base das relações legais, no nível do direito e dos contratos, mas, sim, no plano das disciplinas e de seus efeitos de normalização e moralização (FOUCAULT, 1999), atuando discretamente na produção de realidades e efeitos desejados através dos processos disciplinares e normalizadores. Sendo, portanto, o objetivo de Foucault não a genealogia da constituição do Estado ou do poder soberano, mas a constituição dos sujeitos nesses processos, uma verdadeira ontologia do ser.

Não obstante, o sujeito pensado por Foucault é o produto de uma multiplicidade de relações horizontais de saber-poder que o caracterizam como sujeito 
submetido e disciplinado. Os processos nos quais se produz tal sujeito são instituições, como a escola, a família, os locais de trabalho, o hospital, o exército etc., que reafirmam o controle e a subjetivação. Foucault percebeu que a própria vida se tornou alvo privilegiado da atuação de um poder disciplinar que já não tratava simplesmente de regrar comportamentos individuais ou individualizados, mas que pretendia normalizar a própria conduta dos indivíduos, bem como regrar, manipular, incentivar e observar os fenômenos sociais. Por exemplo, nos programas públicos de massa que remodelaram as condições de vida das populações no final do século XIX e início do XX: o saneamento público; a demolição de favelas; transportes públicos para facilitar o comércio e a mobilidade; bem como os programas de imunização em massa que erradicaram muitas doenças mortais ${ }^{3}$, como a varíola no início do século XX no Brasil ${ }^{4}$. Projetos semelhantes existem hoje, na área da saúde pública como campanhas contra o tabagismo, condução sob o efeito do álcool, bem como alimentação saudável, sexo seguro e a prática de esportes. Que no mundo moderno, não visa somente a "disciplinarização" das condutas, mas também implantar um gerenciamento da vida das populações. Por consequência, o que se produz por meio da atuação específica do biopoder não é mais apenas o indivíduo dócil e útil, mas é a própria gestão calculada da vida no corpo social. (EDKINS e VAUGHAN-WILLIAMS, 2009, p.163-164)

Em sua análise do biopoder, Foucault evidenciou a importante transformação que afetou o próprio poder soberano, a partir do momento em que ele tomou a vida como seu alvo prioritário de investimento. Sua tese consistia que a relação tradicional que o poder soberano havia estabelecido desde a Antiguidade em relação à vida dos súditos poderia ser formulada em termos de um "direito de causar a morte ou de deixar viver" (FOUCAULT, 1988), de tal modo que a vida era apenas a consequência resultante de uma concessão do poder constituído. E ao deixar de exercer seu direito de impor a morte, o poder soberano garantia a vida. Genealogicamente trata-se da forma de atuação de um poder soberano adaptado à figura de uma sociedade na qual o poder se exercia por meio do confisco, apoderando-se de bens, dos corpos e da própria vida dos súditos. A ruptura com este modelo se dá em torno do século XVII, quando Foucault observa o surgimento discreto de um novo mecanismo de exercício do poder, o poder disciplinar. Que possibilitou a formação de uma nova dinâmica, operando um importante deslocamento no poder soberano de impor a morte, nos meados do século XIX. Ou seja, a transformação decisiva que aufere sentido ao biopoder como nova modalidade de exercício do poder soberano, consiste no binômio: poder de "fazer" viver e "deixar" morrer.

Em suma, a partir do momento em que a vida passou a se constituir em elemento político por excelência, por meio da administração, cálculo, regras e normalização, o que se observa não é um decréscimo da violência, como respalda Foucault, muito pelo contrário. Um dos principais exemplos disso é a década de 1990, cujo o ideal imperativo no fim Guerra Fria seria de uma nova ordem internacional pautada no comércio, cooperação e na democracia liberal do tipo ocidental, sem nenhum tipo de grande obstáculo ${ }^{5}$, todavia, as beligerâncias e genocídios como em Ruanda (1994), Bósnia (1992-95) e Kosovo (1998-99), demonstraram que a incessante busca de normalização de um padrão ocidental, majoritariamente, e propriamente cultural (como no leste Europeu) ao almejarem sua "adequação" irromperam em extremadas ações violentas.

Nesse sentido, a análise trazida pelo conceito de biopolítica, tornou-se um dos pontos nodais de alguns pós-modernos para compreensão das relações de poder e dos sujeitos na sociedade contemporânea, principalmente, a capacidade do biopoder para produzir e incentivar de maneira calculada e administrada a vida de uma dada população, bem como sua capacidade de impor o "genocídio/extermínio" aos corpos populacionais considerados exógenos, incorporada de maneira altamente elucidativa por Giorgio Agamben.

\section{A vida nua}

Numa intrínseca relação de complementariedade e de divergências pontuais com as teses de Foucault, Agamben propõe no seu viés analítico, a compreensão político-social que concerne, precisamente, o ponto oculto de interseção entre o modelo jurídico-institucional e o modelo biopolítico do poder. Sendo que essas duas análises não podem ser separadas e suas implicações na vida nua da esfera política constitui núcleo originário - e como mencionado, oculto - do poder soberano. Pode-se dizer, aliás, que a produção de um corpo biopolítico seja a contribuição original do poder soberano. (AGAMBEN, 2007, p. 14) A biopolítica é - nesse sentido - pelo menos tão antiga quanta a exceção soberana: colocando a vida biológica no centro de seus cálculos, logo, o Estado moderno não faz mais, portanto, do que reconduzir à luz o vínculo secreto que une o poder a vida nua, reatando, assim, com o mais imemorial dos arcana imperii (Ibidem). É interessante ressaltar que é neste ponto que filósofo italiano se diferencia do seu homólogo francês em relação ao estabelecimento do biopoder. Cujo advento, para Foucault, se inicia em meados do século XVIII como mencionado anteriormente, e para o pensador italiano, em contrapartida, tal conceito representa algo inerente à política desde a antiguidade, como percebido.

Dessa forma, Agamben refere-se à biopolítica não como advento da modernidade somente, mas da 
própria tradição do pensamento político do ocidente, argumentando que a instituição do poder soberano é correlata à definição do corpo político em termos biopolíticos:

a 'politização' da vida nua é a tarefa metafísica por excelência na qual se decide sobre a humanidade do ser vivo homem, e ao assumir esta tarefa a modernidade não faz outra coisa senão declarar sua própria fidelidade à estrutura essencial da tradição metafísica. O par categorial fundamental da política ocidental não é o de amigo-inimigo, mas antes o da vida nua-existência política, zoe-bios, exclusão-inclusão. Há política porque o homem é o ser vivo que, na linguagem, separa a própria vida nua e a opõe a si mesmo, e, ao mesmo tempo, se mantém em relação com ela em uma exclusão inclusiva. (AGAMBEN, 2007, p.16)

Ao passo que o argumento de Foucault é que - enquanto em Aristóteles a vida e a política são tratadas como separadas - a biopolítica põe em questão a própria ideia de vida: "político não é um atributo do vivente como tal, mas é uma diferença específica que determina o gênero zôon (logo depois, de resto, a política humana a distinguia daquela dos outros viventes porque funda, através de um suplemento de politização ligado a linguagem)" (AGAMBEN, 2007, p. 10). Em outras palavras, para Foucault, a entrada de zoé em bios (estrutura da pólis que reforça a vida qualificada e instituída de direitos) constitui uma mudança fundamental na relação entre política e vida, onde o simples fato de vida, já não está excluído de cálculos e mecanismos políticos, mas reside no cerne da política moderna.

Em vez disso, para Agamben, a produção de um corpo biopolítico é a atividade original do poder soberano. De outro modo, enquanto Foucault observa o movimento da política para biopolítica como uma transformação histórica envolvendo a inclusão de zoé na pólis/bios, para Agamben o domínio político é originalmente biopolítico, pois, já pertence a estrutura essencial da tradição metafísica na política ocidental. Na visão de Agamben, a concepção ocidental da política tem sido marcada pela biopolítica, mas esta relação entre política e vida tornou-se ainda mais visível no contexto do Estado moderno e suas práticas soberanas .(AGAMBEN, 2007, p. 23-25) À vista disso, a origem do elemento biopolítico da política pode ser detectada na definição de Aristóteles da pólis em termos da exclusão entre zoé e bios. Para Agamben, a exclusão de zoé, neste contexto, não é inteiramente "exclusivo". Isto é, porque zoé permanece em uma relação fundamental com bios. $\mathrm{Na}$ verdade, zoé é incluído na bios por sua própria exclusão dele. (EDKINS e VAUGHAN-WILLIAMS, 2009, p. 22) Assim sendo, não estamos lidando com uma exclusão, mas uma "exclusão inclusiva". Para explicar essa noção de Agamben é fulcral percebermos que, se alguém é banido ou proibido de uma dada forma em uma comunidade ele ou ela continua a ter um relacionamento com esse grupo de pessoas: é por meio, precisamente, por causa da proibição que continua a haver uma conexão. A figura da pessoa proibida complica a noção de uma separação clara entre inclusão e exclusão: ele ou ela que é excluído é incluído em virtude de sua própria exclusão.

Levando-se em conta a extensão temporal que ele atribui ao biopoder, permite-se remontar à figura jurídica romana do homo sacer, a vida matável, embora, não sacrificável, sem que tal morte constituísse um crime. Revelando uma região jurídica em que o direito fica suspenso na denominada, vida nua, ao centrar sua reflexão na figura ambígua do soberano, que está, simultaneamente, dentro e fora do ordenamento legal, pelo fato de possuir o poder de declarar o estado de exceção, no qual o ordenamento suprime a lei e se instaura a indiferenciação entre fato e direito, sendo neste imbricamento a exposição da figura do homo sacer, o protótipo da vida nua, supérflua, desprotegida e exposta à morte violenta. (EDKINS e VAUGHANWILLIAMS, 2009, p. 24-28) Tal conceito definido no antigo direito romano, em que o homem que era incluído na legislação na exata medida em que se encontrava totalmente desprotegido por ela: tratava-se daquele indivíduo que, por ser tipificado como homem sagrado, poderia ser morto por qualquer um sem que tal morte constituísse um delito, desde que tal morte não fosse o resultado de um sacrifício religioso ou de um processo jurídico. Para Agamben, portanto, deve-se analisar correlatamente a figura do soberano com a figura do homo sacer, uma vez que o poder soberano implica na vida nua e exposta ao abandono e à morte. Soberano é aquele com respeito ao qual todos os homens são sagrados, isto é, podem ser mortos sem que se cometa homicídio ou sacrifício, ao passo em que o homo sacer, por sua vez, é aquele em relação ao qual qualquer homem pode se comportar como se fosse soberano, pois, qualquer um pode matá-lo. (SOUZA e OLIVEIRA, 2008, p. 75) Assim, se na esfera da soberania pode-se matar sem cometer homicídio e sem celebrá-lo como um sacrifício, reforçando a concepção que a figura do homo sacer é aquela figura sagrada que está duplamente excluída, tanto da ordem divina quanto da humana, e, que sendo insacrificável, está continuamente exposta à morte violenta. Por consequência, constituindo o limiar entre a sacralidade e a bestialidade, entre o sagrado e o profano. (AGAMBEN, 2016)

Deste modo, essa vida do homo sacer é a vida nua, desqualificada de valor e que pode ser aniquilada sem a necessidade de oferecê-la a algum deus em sacrifício ou eliminada sem tipificar um crime, denotando uma profunda correlação entre o poder soberano e a vida nua, uma vez que:

soberana é a esfera na qual se pode matar sem cometer homicídio e sem celebrar um sacrifício, e sacra, isto é, 
matável e insacrificável, é a vida que foi capturada nesta esfera. [...] Aquilo que é capturado no bando soberano é uma vida matável e insacrificável: o homo sacer.[...] Sacra, isto é, matável e insacrificável, é originariamente a vida no bando soberano, e a produção da vida nua é, neste sentido, o préstimo original da soberania. A sacralidade da vida, que se desejaria hoje fazer valer contra o poder soberano como um direito humano em todos os sentidos fundamental, exprime, ao contrário, em sua origem, justamente a sujeição da vida a um poder de morte, a sua irreparável exposição na relação de abandon. (AGAMBEN, 2007, p. 91)

A complementaridade jurídico-institucional junto ao modelo biopolítico do poder soberano ocorre no momento em que o discurso moderno insere a vida biológica, por conseguinte, a vida nua na política em que o poder soberano passa a decidir sobre o seu valor e o não valor, atribuindo elevada importância a determinado tipo de vida como única forma possível de existência, visando, diretamente, tratá-la, regulála e manipulá-la. Na incessante busca de um esquema normalizador cujo objetivo é converter a vida em uma uniformidade padrão, reduzindo ao máximo suas variáveis mutáveis, para torná-la partícipe de uma única totalidade, conforme apontou Foucault. Portanto, a gênese deste processo é reduzir as multiplicidades da vida a uma única forma de vida, na produção de "corpos dóceis" e/ou na simples vida nua, em que ela pode não só ser gerida e calculada, mas também controlada e valorada, determinada dessa forma, de acordo com os preceitos da decisão soberana.

\section{Zoé como prática cotidiana: breves apontamentos}

Agamben e Foucault operam, como podemos perceber, uma análise dos mecanismos contemporâneos de intervenção biopolítica e construções teóricas que se revelam fundamentais ao nos fornecer subsídios para o entendimento de certas questões contemporâneas que nos assolam, em especial no nosso cenário doméstico, como a deflagração da crise do sistema prisional brasileiro em janeiro 2017. Que concentra um total de 662 mil presos para 372 mil vagas. Ao passo que mais de 130 detentos foram mortos nos 20 primeiros dias de 2017 em apenas três presídios ${ }^{6}$.

Esse contexto evidencia a constatação de Agamben de que na atualidade apesar do soberano ser justamente aquele que, dentro da ordem vigente, é capaz de decidir sobre a relevância da vida dos indivíduos, a decisão passa por definir a linha de divisão entre as vidas dignas e as indignas de se viver. O poder soberano, portanto, não mais repousa sob a direção de apenas um sujeito dotado de características excepcionais. $\mathrm{O}$ desenvolvimento das intervenções biopolíticas ocorre cada vez mais de maneira velada, amparadas por um saber-poder que as legitima, e emanadas de centros de poder cada vez mais descentralizados. Incentivando preceitos de aversão a direitos fundamentais como os direitos humanos, no qual determinadas parcelas da população esbravejam a noção de que: "bandido bom é bandido morto", ou até mesmo: "direitos humanos para humanos direitos".

Ao extrapolar o quadro histórico fixado por Foucault, Agamben é incisivo em demonstrar como o biopoder se estende sobre nós desde a antiguidade romana. Assim, todos nós estaríamos ainda hoje, e cada vez mais, submetidos a essa condição de vida nua no interior de um estado de exceção. Apresentando-nos como tênue e instável a linha divisória que desde sempre demarcou a fronteira entre a vida qualificada (bios), a vida que merece ser vivida em plenitude e protegida por ser incluída numa comunidade política (como na pólis) e instituída de direitos; e a mera vida (zoé), a vida nua não qualificada, desprovida de garantias e exposta à morte. Nesse sentido, Agamben observa que - em nosso tempo - o estado de exceção se tornou a regra, pelo fato da política "moderna" comportar fenômenos como o totalitarismo, campos de extermínio, de refugiados, favelas, e a condição dos presidiários. Pontos tão latentes que não passam de vidas zoé para a política e políticos e, para as percepções dos indivíduos no tempo presente. Inserido no regime biopolítico cada vez mais intenso, cuja dinâmica binominal se fixa entre a proteção (bios) e destruição da vida (descartável e matável, a zoé) por meio de sua inclusão excludente dentro do aparato jurídico regulado pelo poder soberano.

\section{Considerações Finais}

O objetivo proposto ao longo deste artigo foi atentar-se quanto à localização do espaço da biopolítica nos contornos da noção do poder soberano e a vida nua. Em que no esquema teórico de Agamben, o poder soberano tributa a prerrogativa de delimitar as fronteiras que separam a vida digna da vida indigna de ser vivida, a vida nua, como já ressaltado. Desta forma é necessário salientar que para Agamben, a produção de um corpo biopolítico é a atividade original do poder soberano. Enquanto, Foucault lê o movimento da política para biopolítica como uma transformação histórica envolvendo a inclusão de zoé na pólis, para Agamben o domínio político é originalmente biopolítico, ou seja, pertencente a uma tradição da própria política ocidental. Todavia, a extensão da teoria foucaultiana em Agamben resulta tangencialmente em certos pontos fulcrais, já mencionados anteriormente, mas dignos de concisão. Em primeiro, a atuação do soberano ao demarcar os limites da vida que deve ser vivida, que é provida por um saber-poder fomentado pelo próprio Estado. Portanto, a própria decisão a respeito dos limites de intervenção biopolítica estatal é 
legitimada por um conhecimento científico, sobretudo o médico e o estatístico, como alertava Foucault. Deste modo, as escolhas são formalizadas como se fossem meramente técnicas e não políticas. Outra menção relevante é a aproximação entre as construções de Agamben e Foucault quanto à fixação pelo Estado dos parâmetros normalizadores. Foucault é hábil e claro ao demonstrar os mecanismos de intervenção biopolítica na delimitação da norma, ou seja, os dispositivos de segurança, que atuam indiretamente sobre o corpo da população, bem como os motivos que possibilitam a gestão calculista e administrativa da vida que visam a uma normalidade. A complementação deste espaço pode ser obtida com a teorização de Agamben a respeito da vida nua: fixando o parâmetro normal que balizará a incidência dos dispositivos de segurança, aqueles que, por critérios médicos e estatísticos categorizam a vida qualificada da indigna - a matável.

Ambos os autores se configuram como cânones no estudo do poder e dos sujeitos - numa incessante busca ontológica -, especialmente, nas relações da mesma com a estética, poder, comportamentos sociais e a ciência (saber-poder). Mesmo que os pensadores trabalhados apresentem variáveis diferentes no percurso de suas metodologias, a essência analítica alcançou um elevado nível complementar, buscaram as suas maneiras, demonstrar a importância do biopoder (e o poder soberano) como uma espécie de articulador dos valores político-sociais, os riscos da total subordinação política e comportamental e a necessidade de uma conscientização engajadora, crítica e de resistência que promova mesmo com o dissenso, um caráter democrático. Contribuindo, assim, para a discussão do conceito, do fazer, visibilidades, discursos e significados do poder, bem como suas imbricações políticas e sociais na sociedade contemporânea.

\section{Bibliografia}

AGAMBEN, Giorgio. Homo sacer: o poder soberano e a vida nua I. Belo Horizonte: Editora UFMG, 2007.

EDKINS, Jenny; VAUGHAN-WILLIAMS, Nick. (Ed.) Critical Theorists and International Relations. New York: Routledge, 2009.

FOUCAULT, Michel. Vigiar e punir. Petrópolis: Vozes, 1977.

Em defesa da sociedade. São Paulo: Martins Fontes, 1999.

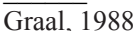

História da Sexualidade: A Vontade de Saber. Rio de Janeiro:

. A governamentalidade. In: Microfísica do poder. Rio de Janeiro: Paz e Terra, 2016. 1977

. O Nascimento da Clínica. Rio de Janeiro: Ed. Forense Universitária,

FUKUYAMA, F. O fim da História e o último homem. Rio de Janeiro: Rocco, 1992.
SOUZA, Ricardo Timm de; OLIVEIRA, Nythamar Fernandes de (Orgs). Fenomenologia hoje: bioética, biotecnologia, biopolítica. Porto Alegre: EDIPUCRS, 2008.

SEVCENKO, Nicolau. A Revolta da Vacina: mentes insanas em corpos rebeldes. São Paulo: Cosac Naify, 2014.

\section{Notas}

1. Observável em Maquiavel na obra "O Príncipe", tese melhor elaborada por Foucault no curso no College de France, em 1 de fevereiro de 1978, intitulado: A governamentalidade. In: Microfísica do poder. Rio de Janeiro: Paz e Terra, 2016.

2. Sociedade moderna para Foucault se caracteriza pela economia capitalista, cientificismo e a disciplina. Sendo que, tais estruturas, exercem poder sobre o homem produzindo subjetividades.

3. Para mais informações sobre o saber cientifico, em especial a clínica médica e das doenças, na atuação dos sujeitos, conforme a compreensão de Foucault, ver: FOUCAULT, Michel. O Nascimento da Clínica. Rio de Janeiro: Ed. Forense Universitária, 1977.

4. A Revolta da Vacina no Brasil é fato muito interessante, ao tomarmos como característica da tese de Foucault, sobre a disciplinarização dos corpos como apresentado ao longo do artigo. Uma vez que a campanha de vacinação era obrigatória, imposta pelo governo federal, com inúmeros casos de violência policial entre outras ações - aos que se opunham a vacinação. Para mais informações e dados sobre a Revolta da Vacina ver: SEVCENKO, Nicolau. A Revolta da Vacina: mentes insanas em corpos rebeldes. São Paulo: Cosac Naify, 2014.

5. Um dos principais difusores desse princípio foi Francis Fukuyama em: FUKUYAMA, F. O fim da História e o último homem. Rio de Janeiro: Rocco, 1992.

6. De acordo com o jornal O Globo. Disponível em: $<$ http://oglobo.globo.com/brasil/as-masmorras-do-brasil20844742\#ixzz4Xw6mm4ME>. Acesso: 23 de março de 2018. 